\title{
PENGARUH LINGKUNGAN KERJA, KEPEMIMPINAN, DAN KOMPENSASI KEPUASAN KERJA PEGAWAI HOTEL DI JAKARTA
}

\author{
Valerie Carina Hartanto dan Joyce Angelique Turangan \\ Program Studi Manajemen, Fakultas Ekonomi dan Bisnis, Universitas Tarumanagara, Jakarta \\ E-mail: valeriecarina98@gmail.com
}

\begin{abstract}
The purpose of this research is to determine the relationship of the relationship of work environment, leadership and compensation on the job satisfaction of employees of five star hotels in Jakarta. The research sample was 100 employees. This research method uses SmartPLS and by distributing questionnaires via google form. The results of this study are that there is a positive and significant influence of work environment, leadership and compensation on the job satisfaction of employees of five star hotels in Jakarta.
\end{abstract}

Keyword: Work Environment, Leadership, Compensation, Job Satisfaction.

Abstrak: Penelitian ini bertujuan untuk mengetahui pengaruh hubungan lingkungan kerja, kepemimpinan dan kompensasi terhadap kepuasan kerja pegawai hotel bintang lima di Jakarta. Sampel penelitian adalah sebanyak 100 pegawai. Metode penelitian ini menggunakan SmartPLS dan dengan cara menyebarkan kuesioner melalui google form. Hasil dari penelitian ini adalah terdapat pengaruh positif dan signifikan lingkungan kerja, kepemimpinan dan kompensasi terhadap kepuasan kerja pegawai hotel bintang lima di Jakarta.

Kata Kunci: Lingkungan Kerja, Kepemimpinan, Kompensasi, Kepuasan Kerja.

\section{LATAR BELAKANG}

Pariwisata adalah salah satu industri yang paling berpotensi untuk dikembangkan di Indonesia, mengingat semakin meningkatnya permintaan produk wisata di Indonesia dari tahun ke tahun. Peningkatan permintaan produk wisata di Indonesia dapat dilihat melalui tingkat kunjungan wisatawan yang terus meningkat tiap tahunnya. Wisatawan mancanegara (wisman) yang berkunjung ke Indonesia selama lima tahun terakhir terus meningkat (www.bps.go.id, 2020). Pada tahun 2018 tercatat sebanyak 15,81 juta kunjungan wisman dan di tahun 2019, angka ini meningkat $1,88 \%$ menjadi 16,11 juta kunjungan. Munculnya pandemi Covid-19 di awal tahun 2020 menyebabkan adanya penurunan wisman yang berkunjung ke Indonesia. Menurut data BPS tahun 2020, jumlah kunjungan wisman ke Indonesia periode Januari-Mei sebesar 2,93 juta atau menurun sebesar 53,56\% dibandingkan dengan jumlah kunjungan wisman tahun 2019 pada periode yang sama. (www.bps.go.id, 2020).

Perkembangan Covid-19 di Indonesia juga berdampak pada banyak sektor, salah satunya sektor pariwisata, khusunya perhotelan. Suatu usaha didirikan bertujuan untuk mendapatkan keuntungan yang maksimal dan produktivitas yang tinggi dengan mutu yang baik. Dalam mencapai tujuan tersebut dan bertahan di masa pandemi, sebuah perusahaan atau organisasi memerlukan modal, sarana dan prasarana, teknologi, serta Sumber Daya Manusia (SDM). Adanya SDM yang baik, akan memberikan kontribusi yang baik pula bagi jalannya suatu organisasi dalam mencapai visi dan misinya, pencapaian produktivitas, dan 
peningkatan mutu organisasi. Keberadaan SDM dapat menjadi ujung tombak bagi keberhasilan suatu organisasi, khusunya di bidang jasa.

Pemanfaatan SDM yang baik berkaitan erat dengan kepuasan kerja pegawai. Apabila pegawai puas akan pekerjaannya, maka produktivitas perusahaan pun juga akan meningkat seiiring dengan peningkatan kinerja pegawai. Menurut Hasibuan dalam Paripurna (2013) tingkat kepuasan kerja pegawai yang tinggi akan membuat pegawai ingin bekerja lebih baik lagi. Kepuasan kerja merupakan suatu hal yang bersifat individual. Tingkat kepuasan seorang pegawai akan berbeda dengan pegawai lainnya. Semakin banyak aspek pekerjaan yang sesuai dengan keinginan individu, maka semakin besar tingkat kepuasan pegawai tersebut.

Salah satu faktor yang dapat mempengaruhi kepuasan kerja adalah lingkungan kerja. Lingkungan kerja adalah tempat pegawai melakukan aktivitasnya yang dapat membawa dampak baik positif maupun negatif bagi pegawai untuk mencapai hasil yang diharapkan. Menurut Ahyari dalam Dwijayanti dan Dewi (2015) faktor yang menentukan pegawai puas dalam bekerja salah satunya adalah kondisi kerja. Kondisi kerja ini meliputi penyinaran yang cukup, suhu udara yang tepat, kenyamanan ruang kerja, dan keamanan pada perusahaan. Menurut Pawirosumarto, Sarjana dan Pawirosumarto (2017), lingkungan kerja memiliki pengaruh yang positif dan signifikan terhadap kepuasan kerja pegawai. Lingkungan kerja yang baik dan kondusif membuat pegawai dapat bekerja secara optimal, sehat, senang, aman, dan efisien.

Selain faktor lingkungan kerja, faktor kepemimpinan juga dapat mempengaruhi kepuasan seseorang dalam bekerja. Gaya kepemimpinan merupakan metode yang digunakan oleh seorang pemimpin untuk mengarahkan perilaku orang lain atau bawahannya demi tercapainya tujuan yang diinginkan. Menurut Nelfan dan Setiawati (2014), kepemimpinan berpengaruh secara positif terhadap kepuasan kerja pegawai. Pemimpin yang baik seharusnya mampu mengarahkan pegawainya dengan baik dan jelas. Apabila seorang pemimpin tidak dapat memberikan arahan atau contoh yang baik kepada pegawai, maka pegawai akan merasa tidak puas dan produktivitas pegawai maupun perusahaan akan menurun.

Kompensasi juga dapat mempengaruhi tingkat kepuasan pegawai, menurut Marwansyah dalam Dwijayanti dan Dewi (2015). Kompensasi disebut juga sebagai penghargaan atau imbalan kepada pegawai baik secara finansial maupun non-finansial yang layak dan adil kepada pegawai sebagai balasan atas kontribusi yang telah diberikan kepada perusahaan. Apabila kompensasi yang diberikan kepada pegawai tepat dan adil, maka tingkat kepuasan pegawai akan meningkat sehingga pegawai termotivasi untuk mencapai tujuan yang diharapkan, dan sebaliknya. Berdasarkan penelitian yang dilakukan oleh Qomariah (2018), terdapat hubungan yang positif antara kompensasi dan kepuasan kerja pegawai.

Di Jakarta, terdapat banyak hotel bintang lima seperti Shangri-La Hotel, Le Meridien, Mandarin Hotel, Double-Tree Hotel, Grand Mercure Hotel, Pullman Hotel dan lainnya. Hotel bintang lima di Jakarta tersebar luas, mulai dari Jakarta Utara, Jakarta Pusat, hingga Jakarta Selatan. Tentunya masing-masing hotel bintang lima ini memiliki brand image tersendiri yang menunjukan bahwa mereka merupakan hotel mewah yang menawarkan berbagai macam akomodasi yang tenang dan nyaman dengan kualitas pelayanan kelas dunia bagi para tamu. Sebagai organisasi yang bergerak di bidang jasa, hotel-hotel tersebut selalu berupaya untuk meningkatkan kepuasan kerja pegawainya.

Pada kenyataannya, terdapat beberapa masalah yang terjadi dalam upaya peningkatan kepuasan kerja pegawai hotel. Salah satunya adalah pemberian kompensasi yang terkadang tidak sesuai dengan yang seharusnya diterima oleh pegawai. Insentif yang diberikan juga 
terkadang dibayarkan tidak tepat waktu. Hal ini menjadikan kepuasan kerja pegawai menurun yang ditunjukan oleh turunnya kedisiplinan pegawai dalam bekerja.

Selain itu, terdapat permasalahan lainnya terkait dengan faktor lingkungan kerja dan kepemimpinan. Beberapa permasalahan terkait dengan lingkungan kerja fisik maupun psikologis yaitu kurangnya penataan ruang kerja, rekan kerja yang pribadinya tidak sesuai satu sama lain sehingga sering terjadi kesalahpahaman, perbedaaan ide atau pandangan antar rekan kerja, dan lain-lain. Lingkungan kerja yang kurang baik inilah yang dapat menurunkan kepuasan kerja pegawai. Hal lain yang dirasakan oleh para pegawai terkait permasalahan faktor kepemimpinan adalah kurangnya diskusi antara atasan dan pegawai dan kurangnya perhatian dari atasan terhadap pegawai yang membuat kepuasan kerja pegawai menurun.

Berdasarkan latar belakang diatas, maka tujuan dari penelitian ini adalah untuk mengetahui apakah Lingkungan Kerja, Kepemimpinan dan Kompensasi dapat digunakan untuk memprediksi Kepuasan Kerja Pegawai Hotel Bintang Lima di Jakarta.

\section{KAJIAN TEORI}

Terkait dengan konsep penelitian yang akan dilakukan ini mengenai kepuasan kerja, teori yang dapat mendukung penelitian adalah Teori Dua Faktor (Two-Factor Theory). Teori yang dikemukakan oleh Frederick Herzberg (1959), menyatakan bahwa terdapat dua faktor untuk menunjukan tingkat kepuasan seorang pegawai yaitu, faktor satisfier atau motivator (motivation factor) dan faktor dissatisfier atau pemeliharaan (hygiene factor). Faktor satisfier adalah faktor intrinsik yang akan meningkatkan kepuasan kerja, sedangkan faktor dissatisfier adalah faktor ekstrinsik untuk mencegah ketidakpuasan pegawai. Faktor satisfier mengarah pada sikap kerja yang positif karena dapat memenuhi kebutuhan aktualisasi diri.

Faktor motivator atau disebut satisfier meliputi dorongan berprestasi, pengakuan, kesempatan untuk berkembang, pekerjaan itu sendiri, tanggung jawab, dan kemajuan. Faktor kebersihan atau disebut dissatisfier meliputi kondisi lingkungan kerja, kompensasi, keamanan dan status dalam bekerja, kualiatas atasan, hubungan antar rekan kerja, serta hubungan antara atasan dan pegawai. Prinsip dari teori ini adalah meningkatkan faktor motivator untuk meningkatkan kepuasan kerja pegawai, dan meningkatkan faktor pemeliharaan untuk menurunkan ketidakpuasan kerja pegawai.

Lingkungan kerja merupakan kondisi lingkungan kerja dikatakan baik atau sesuai apabila manusia dapat melaksanakan kegiatan secara optimal, sehat, aman, dan nyaman (Nursasongko, 2012). Lingkungan kerja yang mendukung dapat membantu pegawai mengerjakan tugasnya lebih efektif, dan memanfaatkan pengetahuan, keterampilan dan kompetensi mereka serta sumber daya yang tersedia sebaik-baiknya untuk memberikan layanan berkualitas tinggi.

Kepemimpinan adalah kemampuan seseorang untuk mempengaruhi orang lain (para bawahannya) sedemikian rupa sehingga orang lain itu mau melakukan kehendak pemimpin meskipun secara pribadi hal itu mungkin tidak disenanginya (Siagian, 2002). Kepemimpinan merupakan sebuah proses atau cara yang digunakan oleh seorang pemimpin untuk mempengaruhi perilaku bawahan atau pegawainya.

Kompensasi merupakan penghargaan atau imbalan langsung maupun tidak langsung, financial maupun non financial yang adil dan layak kepada karyawan, sebagai balasan atas kontribusi atau jasanya terhadap pencapain tujuan organisasi (Marwansyah, 2012). Kompensasi juga dapat diartikan sebagai suatu pemberian kepada karyawan dengan 
pembayaran finansial sebagai balas jasa untuk pekerjaan yang dilakukan dan sebagai motivator untuk pelaksanaan kegiatan di masa yang akan datang (Simamora, 2006).

Kepuasan kerja adalah perasaan yang dimiliki karyawan terhadap pekerjaan dan segala sesuatu yang berkesan dalam pekerjaan tersebut (Kurniawati, 2005). Kepuasan kerja merupakan perasaan atau sikap positif yang dimiliki oleh pegawai terhadap pekerjaannya. Indikator yang digunakan dalam penelitian ini yaitu pekerjaan (work), gaji (wage), atasan (supervisor), rekan kerja (co-worker $\neg)$, dan promosi (promotion)

Berikut pada Gambar 2.1 di bawah ini merupakan kerangka pemikiran yang akan dijalankan pada penelitian:

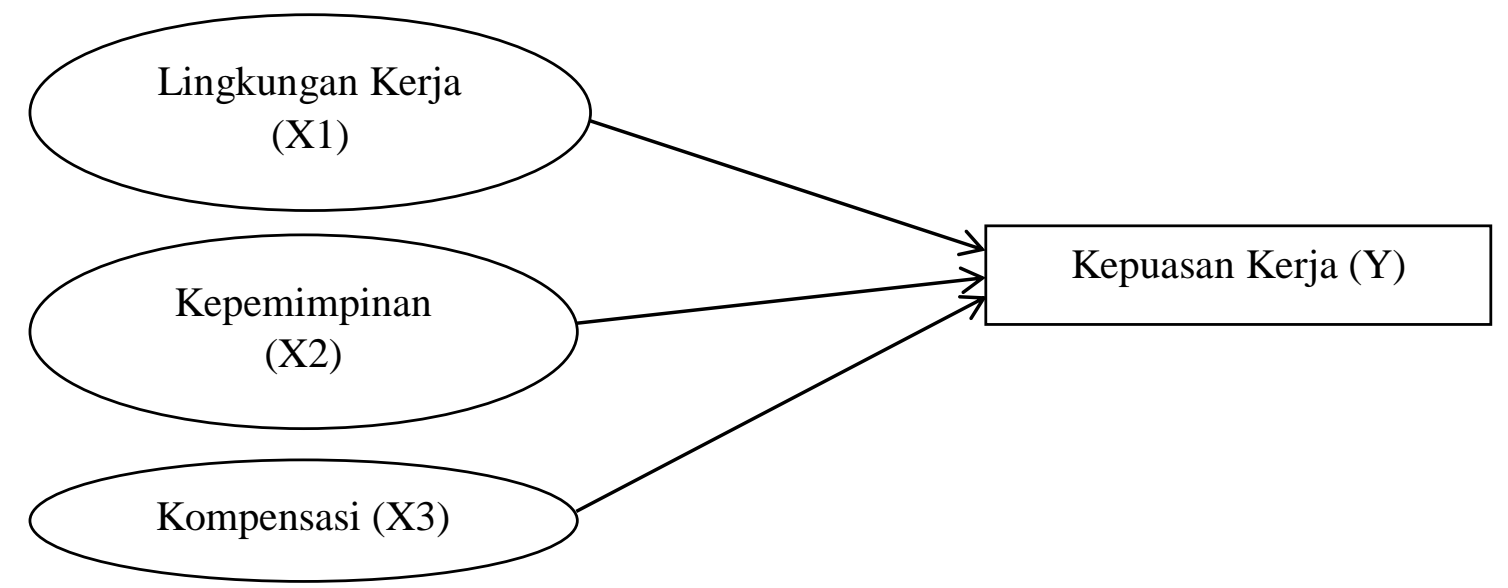

Gambar 2.1. Kerangka Pemikiran

Hipotesi yang akan dirumuskan berdasarkan Gambar 2.1 adalah sebagai berikut:

H1: Lingkungan kerja memiliki pengaruh yang positif terhadap kepuasan kerja.

H2: Kepemimpinan memiliki pengaruh yang positif terhadap kepuasan kerja.

H3: Kompensasi memiliki pengaruh yang positif terhadap kepuasan kerja.

\section{METODOLOGI}

Pada penelitian ini tipe desain penelitian yang akan digunakan adalah desain penelitian deskriptif. Menurut Aritonang R., dalam Liadi dan Budiono (2019), penelitian deskriptif merupakan penelitian yang tidak ada variabel yang dimanipulasi atau disebut juga sebagai perlakuan (treatment). Penelitian ini, peneliti menggunakan cross-sectional design. Malholtra dalam Christian dan Darmawan (2019) menyatakan bahwa "desain crosssectional adalah jenis desain penelitian yang melibatkan pengumpulan informasi dari sampel elemen populasi tertentu saja sebanyak satu kali." Jadi, konsekuensi dari desain penelitian deskriptif jenis cross sectional adalah hasil penelitian belum tentu berlaku pada masa yang akan datang, karena studi cross sectional dilaksanakan dalam jangka waktu yang relatif singkat.

Aritonang R., dalam Sunanto (2016) menyatakan bahwa "keseluruhan unsur yang menjadi subjek dalam suatu penelitian disebut populasi, sedangkan bagian dari populasi disebut sampel." Berdasarkan pernyataan tersebut, populasi merupakan seluruh unsur yang menjadi subjek dalam penelitian. Pada penelitian ini, populasi yang digunakan pegawai hotel bintang 5 di Jakarta yang bekerja di Shangri-La Hotel, Le Meridien, Mandarin Hotel, 
Double-Tree Hotel,dan Pullman Hotel. Populasi pegawai hotel bintang 5 tersebut cukup besar dan tidak memungkinkan untuk meneliti keseluruhan populasi, sehingga peneliti akan mengambil sampel dari keseluruhan populasi yang ada. Dalam memilih sampel yang akan diteliti, maka peneliti menggunakan metode non-probability sampling, yaitu tiap-tiap anggota populasi tidak memiliki kesempatan yang sama untuk dipilih sebagai sampel (Aritonang dalam Chandra dan Budiono, 2019). Peneliti menggunakan metode tersebut didasarkan pada alasan adanya keterbatasan waktu dan biaya. Teknik pemilihan sampel yang digunakan pada penelitian ini adalah convenience sampling.

Mengacu pada pedoman sampel yang dikemukakan oleh Roscoe dalam Sekaran dan Bougie (2016), sampel yang tepat berkisar dari 30 sampai dengan 500. Oleh karena itu, pada penelitian ini jumlah sampel yang akan diteliti berjumlah 100 responden.

Dalam memperoleh data maka penelitian ini akan menggunakan kuisioner sebagai cara memperoleh data dari para responden. Untuk setiap pengukuran terhadap masing-masing variabel pada penelitian ini berdasarkan acuan yang kemudian diterjemahkan kedalam bahasa Indonesia. Skala yang digunakan dalam penelitian adalah interval. Lingkungan kerja diukur berdasarkan acuan dari (Sedarmayanti, 2011). Kepemimpinan diukur berdasarkan acuan dari (Pawirosumarto et al., 2016). Kompensasi diukur berdasarkan acuan dari (Mathis dan Jackson, 2011). Kepuasan Kerja diukur berdasarkan acuan dari (Pawirosumarto et al., 2016).

Dalam penelitian ini proses analisis data akan dilakukan dengan menggunakan program partial least square (PLS). Penelitian ini dalam mengelolah data dan menganalisis data akan menggunakan software smart partial least square (PLS) versi 3.00. Dalam penganalsisan data dengan PLS dibagi menjadi dua pengujian yakni outer model dan inner model. Outer model merupakan pengujian yang digunakan untuk melihat hasil uji validitas dan uji relibilitas. Uji inner model yang terdiri dari uji koefisien determinan $\left(\mathrm{R}^{2}\right)$, uji effect size $\left(f^{2}\right)$, uji pengukuran Q-Square $\left(Q^{2}\right)$, uji kecocokan model (Gof), uji path coefficient (pengujian hipotesis), uji mediasi.

\section{HASIL ANALISIS DATA}

Penelitian ini melibatkan 100 responden pegawai hotel bintang lima yang terletak di Jakarta. Dari total 100 responden, terdapat 41 orang responden berjenis kelamin pria, dan 59 orang responden berjenis kelamin wanita. Mayoritas responden berdomisili di Jakarta Selatan dan berusia 20 sampai 30 tahun, serta memiliki pendidikan terakhir SMA/Sederajat. Penelitian ini menggunakan skala likert dalam menunjukan pernyataan yang dirasakan oleh responden yakni dimulai dari satu sampai lima dengan keterangan bahwa satu merupakan sangat tidak setuju dan lima adalah sangat setuju. Berdasarkan hasil tanggapan dari responden maka diperoleh hasil dari pengujian outer model yakni pengujian validitas yang terdiri dari loading factor dan average variance extracted (AVE) dari setiap indikator. Hasil AVE dari masing-masing variabelnya yang digunakan pada penelitian ini dapat dinyatakan baik karena nilai pada setiap variabelnya adalah diatas 0,5 . Selanjutnya pada pengujian validitas terdapat pengujian discriminant validity. Oleh karena itu pengukuran yang dapat menunjukan nilai dari discriminant validity adalah fornell larcker dan cross loading. Hasil dari nilai fornell larcker ini membuktikan bahwa korelasi antar konstruk memiliki nilai lebih kecil sehingga konstruk yang dihasilkan lebih besar sehingga dari hasi pengujian fornell larcker dapat dikatakan valid. Hasil dari pegujian cross loadings pada penelitian ini sudah memenuhi syarat suatu indikator tersebut telah valid dengan hasil nilai dari cross loadings variabel dengan indikatornya yang dihasilkan lebih besar dari nilai variabel tersebut dibanding dengan indikator variabel lain. Pengujian selanjutnya terkait dengan 
outer model yakni uji reliabilitas yang dilihat berdasarkan hasil composite reliability. Hasil dari composite reliability sudah lebih dari 0,7 . Sehingga variabel dalam penelitian ini dapat dikatakan reliabel.

Berdasarkan hasil tanggapan dari responden maka diperoleh hasil dari pengujian inner model yang pertama adalah uji $\mathrm{R}^{2}$. Hasil uji $\mathrm{R}^{2}$ menunjukkan bahwa sebesar 0,786 atau $78,6 \%$ variabel kepuasan kerja dapat dijelaskan oleh lingkungan kerja, kepemimpinan dan kompensasi secara kuat. Sisanya sebesar $21,4 \%$ dapat dijelaskan oleh variabel lain. Hasil pada pengujian effect size $\left(f^{2}\right)$ menyatakan bahwa variabel lingkungan kerja, kepemimpinan dan kompensasi memiliki efek lemah, sedang, dan kuat terhadap variabel kepuasan kerja. Hasil dari predictive relevance $\left(\mathrm{Q}^{2}\right)$ sebesar 0,507 . Hasil ini menunjukan bahwa variabelvariabel yang ada dalam penelitian ini dapat memprediksi model penelitian dengan baik karena hasil nilai $\mathrm{Q}^{2}>0$. Selanjutnya pengujian terhadap nilai kecocokan model (GoF) pada penelitian ini hasil dari pengujian adalah 0,7685 yang dapat menyatakan bahwa kecocokan dalam model penelitian ini dapat dinyatakan besar. Dalam menjawab hipotesis maka pengujian yang dilakukan adalah dengan path coefficient dengan melihat hasil dari $\mathrm{T}$ statistic dan p-values. Pada hasil penelitian ini terlihat bahwa pada variabel lingkungan kerja, kepemimpinan dan kompensasi dapat memprediksi kepuasan kerja secara langsung. Berikut ini disajikan tabel hasil dari pengujian path coefficient dengan menggunakan teknik bootstrapping untuk menjawab setiap hipotesis pada penelitian.

Tabel 1. Hasil Path Coefficient

\begin{tabular}{|c|c|c|c|}
\hline Variabel & Path Coefficient & t-statistics & $\boldsymbol{p}$-values \\
\hline $\begin{array}{c}\text { Lingkungan Kerja } \rightarrow \\
\text { Kepuasan Kerja }\end{array}$ & 0,240 & 2,022 & 0,044 \\
\hline $\begin{array}{c}\text { Kepemimpinan } \rightarrow \\
\text { Kepuasan Kerja }\end{array}$ & 0,346 & 2,502 & 0,013 \\
\hline $\begin{array}{c}\text { Kompensasi } \rightarrow \\
\text { Kepuasan Kerja }\end{array}$ & 0,465 & 4,136 & 0,000 \\
\hline
\end{tabular}

*Sumber: Olahan data Smart-PLS versi 3.000

\section{DISKUSI}

Hasil hipotesis telah menunjukkan nilai $T$-statistic dan nilai $p$-values. Pada bagian ini akan dilakukan pembahasan yang berkaitan dengan hipotesis pada penelitian ini. Dengan total jumlah responden pada penelitian ini adalah 100 responden, maka berikut ini akan dilakukan pembahasan terkait dengan hasil pengujian hipotesis:

H1. Lingkungan kerja memiliki pengaruh yang positif terhadap kepuasan kerja. Hasil pengujian $\mathrm{H} 1$ menunjukkan bahwa variabel lingkungan kerja merupakan prediktor yang positif dan signifikan terhadap variabel kepuasan kerja, dengan nilai original sample sebesar 0,240 , nilai t-statistics $\neg$ sebesar 2,022, dan nilai p-values sebesar 0,044 . Hal ini mendukung penelitian yang dilakukan oleh Sedarmayanti (2011) bahwa variabel lingkungan kerja dapat memengaruhi kepuasan kerja secara positif dan signifikan. Apabila lingkungan kerja yang dirasakan oleh pegawai baik, maka kepuasan kerjanya pun akan meningkat. Hal ini sesuai dengan teori dua faktor (two factor theory) yang dikemukakan oleh Herzberg (1959), bahwa 
faktor pemeliharaan seperti lingkungan kerja harus ditingkatkan untuk menurunkan ketidakpuasan kerja pegawai.

H2. Kepemimpinan memiliki pengaruh yang positif terhadap kepuasan kerja. Hipotesis kedua yakni $\mathrm{H} 2$ menunjukan hasil menunjukan bahwa variabel kepemimimpinan dapat menjadi prediktor positif dan signifikan terhadap variabel kepuasan kerja dengan nilai original sample sebesar 0,346 , nilai t-statistics 7 sebesar 2,502, dan nilai p-values sebesar 0,013. Hal ini memiliki arti bahwa setiap hotel harus memiliki kepemimpinan yang baik untuk meningkatkan kepuasan kerja pegawainya. Hasil ini sejalan dengan hasil penelitian yang dilakukan oleh Pawirosumarto et al., (2016), bahwa adanya pemimpin mampu mengarahkan pegawainya dengan baik akan meningkatkan kepuasan kerjanya. Pegawai akan merasa dihargai dan dibutuhkan. Hasil yang sama juga terdapat pada penelitian yang dilakukan oleh Mindari (2018), bahwa kepemimpinan dapat memengaruhi kepuasan kerja secara signifikan, sehingga kepemimpinan merupakan hal penting yang harus diperhatikan untuk meningkatkan kepuasan kerja pegawainya.

H3. Kompensasi memiliki pengaruh yang positif terhadap kepuasan kerja. Berdasarkan hasil pengujian bootstraping yang ditunjukan pada gambar 4.2 dan tabel 4.11, nilai path coefficient variabel kompensasi sebesar 0,465, nilai t-statistics $\neg$ sebesar 4,136 atau lebih besar dari 1,96 dan nillai p-values sebesar 0,000 atau kurang dari 0,05. Hasil ini menunjukan bahwa variabel kompensasi dapat memprediksi kepuasan kerja secara positif dan signifikan, sehingga $\mathrm{H} 3$ tidak ditolak.

\section{PENUTUP}

Dalam mencapai penelitian ini dengan menetapkan sampel sebanyak 100 responden yang merupakan pegawai hotel bintang lima di Jakarta. Setelah melalui pengujian dan memperoleh hasil beserta pembahasan yang telah dilakukan, maka peneliti memperoleh kesimpulan sebagai berikut :

1. Lingkungan kerja memiliki pengaruh yang positif dan signifikan terhadap kepuasan kerja. Hasil pengujian path coefficient menunjukkan nilai original sample dan $t$ statistics masing-masing sebesar 0,240 dan 2,022 (> 1,96).

2. Kepemimpinan memiliki pengaruh yang positif dan signifikan terhadap kepuasan kerja. Hasil pengujian path coefficient menunjukkan nilai original sample dan t-statistics masing-masing sebesar 0,346 dan 2,502 (> 1,96).

3. Kompensasi memiliki pengaruh yang positif dan signifikan terhadap kepuasan kerja. Hasil pengujian path coefficient menunjukkan nilai original sample dan $t$-statistics masing-masing sebesar 0,465 dan 4,136 (>1,96).

Berdasarkan hasil penelitian yang telah diperoleh dan dibahas serta keterbatasan yang masih dirasakan peneliti, maka peneliti dapat memberikan beberapa saran yang diharapkan dapat bermanfaat bagi pemilik UMKM dalam bidang fashion yang berada di Jakarta Barat maupun bagi penelitian sejenis lainya. Adapun saran dari peneliti sebagai berikut :

Berdasarkan hasil penelitian yang telah dilakukan pada penelitian ini, maka terdapat beberapa saran yang kiranya dapat bermanfaat bagi organisasi perhotelan dan peneliti selanjutnya. Adapun saran yang dapat diberikan sebagai berikut:

\section{Bagi Organisasi Perhotelan}

Pemilik-pemilik hotel disarankan untuk meningkatkan kepuasan kerja pegawainya, khususnya dari segi lingkungan kerja, kepemimpinan, dan kompensasi yang diberikan. Lingkungan kerja yang kondusif akan memberikan rasa nyaman dan puas dalam 
bekerja. Hal itu dapat dilakukan dengan cara menata ulang ruang kerja agar lebih rapih dan nyaman, memberikan hiasan dalam ruang kerja agar ruang terlihat lebih hidup, memerhatikan pencahayaan ruang apakah sudah cukup atau belum, dan membina hubungan baik antar rekan kerja. Penting pula bagi pemilik hotel untuk memerhatikan gaya kepemimpinan yang baik. Hal ini dapat dilakukan melalui pembinaan hubungan antara atasan dan bawahan, sehingga tercipta hubungan yang harmonis. Hubungan inilah yang dapat meningkatkan kepuasan pegawai dalam bekerja.

Peneliti juga menyarankan agar pemilik hotel bisa memerhatikan faktor kompensasi yang akan diberikan kepada setiap pegawai. Hal ini bisa dilakukan dengan cara membayarkan gaji tepat waktu, memberikan tunjangan dan pesangon serta fasilitas yang memadai untuk memudahkan pegawai dalam bekerja. Dengan demikian, pegawai akan merasa dihargai dan puas dalam bekerja. Kinerja pegawai pun akan meningkat seiring meningkatnya kepuasan kerja pegawai.

\section{Bagi Penelitian Selanjutnya}

Untuk penelitian selanjutnya, diharapkan dapat menambah jumlah responden, mengingat jumlah hotel bintang lima di Jakarta sangat banyak. Selain itu, peneliti berharap agar penelitian selanjutnya dapat mengeksplor variabel independen lain selain lingkungan kerja, kepemimpinan dan kompensasi untuk memprediksi kepuasan kerja. Variabel independen lainnya dapat berupa motivasi, stress kerja, komunikasi, budaya organisasi, dan lainnya.

\section{DAFTAR PUSTAKA}

http://www.bps.go.id. (2020) BPS: Jumlah Kunjungan Wisman ke Indonesia Desember 2019Bps.go.id. diakses pada tanggal 11 Oktober 2020. https://www.bps.go.id/pressrelease/2020/02/03/1711/jumlah-kunjungan-wisman-keindonesia-desember-2019-mencapai-1-38-juta-kunjungan-.html.

http://www.bps.go.id. (2020) BPS: Jumlah Kunjungan Wisman ke Indonesia Mei 2020Bps.go.id. diakses pada tanggal 11 Oktober 2020. https://www.bps.go.id/pressrelease/2020/07/01/1716/jumlah-kunjungan-wisman-keindonesia-mei-2020-mencapai-163-65-ribu-kunjungan-.html.

Ashraf, M. A. (2020). Demographic factors, compensation, job satisfaction and organizational commitment in private university: an analysis using SEM. Journal of Global Responsibility.

Barry, R. and Heizer, J. (2001). Prinsip-prinsip manajemen operasi: Operations Management, Salemba Empat, Jakarta.

Brahmasari, I. A., \& Suprayetno, A. (2008). Pengaruh motivasi kerja, kepemimpinan dan budaya organisasi terhadap kepuasan kerja karyawan serta dampaknya pada kinerja perusahaan (studi kasus pada pt. pei hai international wiratama indonesia). Jurnal Manajemen dan Kewirausahaan, 10(2), 124-135.

Chandra, R. A., \& Budiono, H. (2019). Pengaruh pendidikan kewirausahaan terhadap niat berwirausaha yang dimediasi efikasi diri mahasiswa manajemen. Jurnal Manajerial Dan Kewirausahaan, 1(4), 645-655.

Diatmika Paripurna, I. G. Pengaruh kepemimpinan, lingkungan kerja dan komunikasi terhadap kepuasan kerja karyawan. E-Jurnal Manajemen Universitas Udayana, 2(5).

Dwijayanti, M. N., \& Dewi, A. S. K. (2015). Pengaruh kompensasi dan lingkungan kerja terhadap kepuasan kerja karyawan pada perusahaan daerah air minum tirta mangutama badung. E-Jurnal Manajemen Universitas Udayana, 4(12). 
House, R. \& Wigdor, L. (1967). Herzberg's dual-factor theory of job satisfaction and motivation: A review of the evidence and criticism. Personnel Psychology, 20(4), 369-389.

Ivancevich, J.M., Konopaske and R., Matteson, M.T. (2008), Organizational Behavior and Management, 8th ed, McGraw-Hill, NY.

Jeanette, F., Patricia, F. and Robert, S. (2013), "Occupational pay comparisons - easier said than done?”, Employee Relations: An International Journal, Vol. 36 No. 1, pp. 2-16.

Kreitner, R. and Kinicki, A. (2008), Organizational Behavior, 8th ed., McGraw-Hill, Boston, MA. Kristanti and Harah.

Kristanti and Harahap, P. (2012), "Pengaruh gaya kepemimpinan, komunikasi dan motivasi kerja terhadap kinerja karyawan (studi pada PT. Bank tabungan pensiunan nasional cabang semarang)", Dinamika Manajemen USM, Vol. 1 No. 1, pp. 16-28.

Leshabari M, Muhondwa E, Mwangu M, Mbembati N. (2008). Motivation of health care workers in tanzania: case study of muhimbili national hospital. East African journal of Public Health, 5 (1): 30-36.

Liadi, F. N., \& Budiono, H. (2019). Pengaruh dukungan pendidikan, sikap dan efikasi diri terhadap intensi kewirausahaan pada mahasiswa semester satu. Jurnal Manajerial Dan Kewirausahaan, 1(3), 447-455.

Mathis, R. L., and Jackson, J. H. (2011). Human Resources Management. Jakarta: Salemba Empat.

Mehboob Syed Ali Abdullah, Anwar Adeel, and Hijazi Syed Tahir. 2009. Impact of nonfinancial reward on employee motivation: a case of cellular communication service providing sector of telecom industry registered under pta in islamabad). Cambridge Journal of The Business Review, 7(2): pp:272-277.

Michael Christian, T., \& Darmawan, H. (2019). Mulut ke mulut dan citra merek untuk memprediksi niat beli pada konsumen laptop asus di fakultas ekonomi universitas tarumanagara. Jurnal Manajerial Dan Kewirausahaan, 1(3), 559-568.

Nelfan, D., \& Setiawati, M. (2014). Analisis pengaruh lingkungan kerja, kepemimpinan, dan motivasi terhadap kepuasan kerja karyawan food and beverage " $\mathrm{x}$ " hotel surabaya. Jurnal Hospitality dan Manajemen Jasa, 2(1), 127-145.

Nursasongko, Ginanjar.S. (2012). Analisis pengaruh kepemimpinan, lingkungan kerja dan kompensasi terhadap kinerja pegawai (studi pada badan kepegawaian daerah kabupaten pemalang. Unpublished undergraduate thesis, Universitas Diponegoro, Semarang.

Pawirosumarto, S., Sarjana, P. K., \& Gunawan, R. (2017). The effect of work environment, leadership style, and organizational culture towards job satisfaction and its implication towards employee performance in Parador Hotels and Resorts, Indonesia. International Journal of Law and Management.

Permadi, K. O., Landra, N., Kusuma, G. A. E. T., \& Sudja, N. (2018). The impact of compensation and work environment towards job satisfaction to affect the employee performances. International Journal of Management and Commerce Innovations, $6(2)$.

Rumada, G., \& Utama, I. W. M. (2013). Pengaruh kompensasi, kepemimpinan, dan lingkungan kerja fisik terhadap kepuasan kerja karyawan hotel Taman Harum Ubud Gianyar. E-Jurnal Manajemen Universitas Udayana, 2(1).

Sekaran, U., \& Bougie, R. (2016). Research methods for business: A skill building approach. John Wiley \& Sons.

Simamora Henry. 2006. Manajemen Sumber Daya Manusia. Cetakan kedua. Yogyakarta: STIE TKPN. 
Sunanto, S. (2016). Pengaruh penetapan harga dan kualitas layanan terhadap kepuasan pelanggan pada apotik sunfarma tangerang selatan. inovasi, 3(2).

Qomariah, N. (2018). Pengaruh lingkungan kerja, motivasi dan kompensasi terhadap kepuasan kerja karyawan. JAMSWAP, 3(2), 21-32 